\title{
Impact of Innovations on Future Energy Supply - Chemical Enhanced Oil Recovery (CEOR)
}

\author{
Christian Bittner*
}

\begin{abstract}
The International Energy Agency (IEA) expects an increase of global energy demand by one-third during next 20 years together with a change in the global energy mix. A key-influencing factor is a strong expected increase in oil and gas production in the United States driven by 'new' technologies such as hydraulic fracturing. Chemical enhanced oil recovery (CEOR) is another strong growing technology with the potential of a step change innovation, which will help to secure future oil supply by turning resources into reserves. While conventional production methods give access to on average only one-third of original oil in place, the use of surfactants and polymers allows for recovery of up to another third of this oil. In the case of polymer flooding with poly acrylamide, the number of full field implementations has increased in recent years. In the meantime new polymers have been developed to cover previously unmet needs - such polymers can be applied in fields of high salinity and high temperature. Use of surfactants is in an earlier stage, but pilot tests show promising results.
\end{abstract}

Keywords: Alkaline surfactant polymer flooding · Enhanced oil recovery · Oil \& gas · Polymer flooding

\section{Importance of Crude Oil}

In the last century a tremendous shift took place as crude oil replaced coal as the most important fossil fuel, as described by Yergin in a very impressive way. ${ }^{[1]}$ Huge amounts of oil were available from the end of $19^{\text {th }}$ till mid-20 $0^{\text {th }}$ century. Compared to coal, for a long time oil was cheaper and engines with mineral oil as fuel ran better and faster. Especially the last point was of high significance for mobility - use in civil or military purposes. After the Second World War crude oil from the Middle East enabled competitive industry in Europe to be quickly rebuilt. In 2011 global oil consumption reached a level of 87.4 million barrels per day. ${ }^{[2]}$ The transportation sector is currently responsible for more than half of crude oil consumption. ${ }^{[2,3]}$ Passenger cars, trucks, ships, airplanes and some

${ }^{*}$ Correspondence: Dr. C. Bittner

BASF SE

GMM/S - J550

D-67056 Ludwigshafen

Germany

Tel.: +496216079232

E-mail: christian.bittner@basf.com trains rely on mineral oil products such as diesel. The same is true for the vehicles in the food production sector. [3] For household heating oil is still used on a significant level, but other sources such as natural gas are more dominant. ${ }^{[4]}$

\section{Interesting Changes in the Future}

The International Energy Agency (IEA) published its annual world energy outlook at the end of 2012 [2] and predicted that global energy demand will increase by at least $30 \%$ during the next 20 years, mainly driven by the fast-growing countries in Asia (e.g. China, India). Despite significant regional differences, global oil consumption will grow mainly due to transportation of people and freight. The number of cars will double, and more and more diesel trucks, in particular, will be needed for transportation of goods (a result of booming economies and increased private consumption caused by elevated living standards). With regard to passenger cars other power sources such as electricity can have a significant share as pointed out by Yergin. ${ }^{[5]}$ However, it is expected by IEA that 99.7 million barrels crude oil per day will be needed in 2035 (versus 87.4 million barrels per day in 2011). Much will depend on Iraq and its capability to strongly enlarge its oil production. Not many new oil fields have been discovered in the last years, and many reservoirs operated by established processes are starting to decline in production. As a matter of consequence, one would assume that the task of increasing global oil production would be challenging. However, IEA has described a very surprising exit scenario, which would have been unthinkable just a couple of years ago. Of all countries United States of America (USA) will become in roughly 10 years from now on the largest oil producer of the world. ${ }^{[2]}$ What are the reasons?

\section{Innovations for Unlocking Condensates and Tight Oil in USA}

An innovation is an invention that is successful in the market. ${ }^{[6]}$ It includes also the case where basics of the technology used have been known for long time, but other important factors did not fit. This could be, for example, missing further development of technology to match current challenges, price, legislation, competing technologies and so on. But if all things come together an innovation can take place. This was the case with hydraulic fracturing, which has been known since end of the 1940s. It was, however, fifty years later when Mitchell Energy found out how to use this technology to break up shale rock and produce shale gas - an unconventional resource. ${ }^{[5]}$ Combined with the horizontal drilling technique, huge amounts of gas have been made accessible with the effect that shale gas has become cheaper than natural gas. In fact, the strong oversupply of the market has led to a decrease in the economics of many shale gas projects. Therefore, the focus has shifted to gas reservoirs, which also 
contain liquid compounds - so-called condensates. Their quality is comparable with high-quality light oil, and condensates can be sold at a high price. In 2010 roughly 10 million barrels per day were produced. ${ }^{[5]}$ During the next 20 years this rate could almost double. However, since the production rate declines after a certain point, a significant number of new wells will have to be drilled to maintain the production rate. Hydraulic fracturing combined with horizontal drilling is also used to produce tight oil. Hess has started to work on in this area and in 2010 produced 400,000 barrels per day from a formation in USA called Bakken. Taking into account other formations in the USA, production could be fivetimes higher in 2020.

Beside the attractiveness of shale gas production there is also a debate on its environmental consequences, as mentioned by Yergin. ${ }^{[5]}$

\section{Chemical Enhanced Oil Recovery}

There are also alternative technologies, which could have a significant impact on future energy supplies. One strong, growing technology to maintain or even improve total oil production is chemical enhanced oil recovery (CEOR). It is applied in developed conventional oil fields with known petroleum reserves. In case of water flooded fields, most of the infrastructure for CEOR is already in place. Compared to exploration of an unknown field, investment risk is strongly reduced. To put it in other words, CEOR has the potential of a step change innovation.

Before going into further details, first of all some basics about the production process in conventional fields are mentioned. Oil recovery can be divided into three different stages. ${ }^{[7]}$ Primary recovery is driven by natural forces that are present in the reservoir, which can be a natural gas cap or an aquifer. These forces push oil towards the producing well. Usually only $5-10 \%$ of original oil in place (OOIP) can be produced. Once the pressure drops additional wells are drilled, and water, for example, is injected to re-increase pressure. This phase of production is called secondary recovery. More oil is produced (incremental oil), but over time water breaks through. Oil is bypassed and water flows directly from the injector to the producer well - the so-called water cut increases with time. Fig. 1 shows breakthrough of water leading to a by-pass of oil-bearing zones. Sooner or later much more water than oil is produced, and the water cut can go up to $90 \%$ or higher. With secondary oil recovery (water flooding or injection of immiscible gas to maintain pressure) another 20-25\% of OOIP are on average accessible.

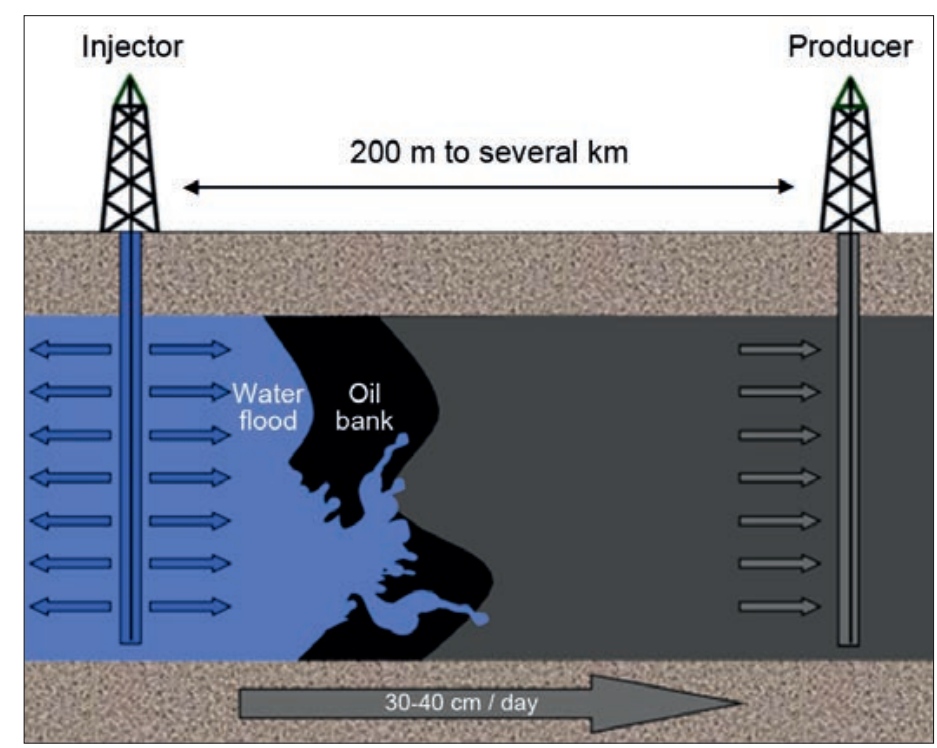

Fig. 1. Water flooding.

At a certain oil price level other methods also become economical. These methods are summarized under the field of tertiary oil recovery, also known as enhanced oil recovery (EOR). They cover use of steam, gas, microbes, or chemicals. Depending on the geology of the reservoir and the oil quality, chemical enhanced oil recovery (CEOR) has the potential to produce much more OOIP than other EOR methods. On average up to another one-third of OOIP can be produced by use of chemicals such as surfactants and polymers. This means high production rates can be maintained in mature fields over a long time, and ultimate recovery yields can be significantly improved. As this amount is similar to that of primary and secondary recovery, up to $65 \%$ of OOIP is accessible in total (by combination of primary, secondary, and chemical enhanced oil recovery).

CEOR is not a new technology. As shown in Fig. 2, during the oil crisis in the 1970s production could not keep pace with the increase in price. ${ }^{[8]}$ In this time basic research programs were started to explore use of suitable surfactants and polymers for enhanced oil production. After the oil price dropped mid-1980s, CEOR was not economic anymore, and most activities were stopped. Due to a huge price increase at the beginning of the new century, CEOR became attractive again, even on a longterm perspective. Research activities have been restarted. In addition polymers and surfactants have been developed further to enable their use under demanding field conditions and thereby to cope with previously unmet market needs.

\section{Remaining Oil Saturation \& Capillary Number}

Oil production is affected by several factors such as well arrangement between injector and producer, type of rock and its heterogeneity, or the quality of the oil. As shown in Fig. 1 the injection of water leads to only a certain level of oil production. On a macroscopic level, the displacement of oil by water is inefficient, because water mobility is higher than the mobility of oil. Water usually has a lower viscosity compared to crude oil, and it flows through the ground more easily. On a microscopic level another factor plays an important role - the so-called capillary number $N{ }^{\left[{ }^{[8]}\right.}$ One has to keep in mind that crude oil is located in porous rocks such as sandstone or carbonate. The capillary number $N_{c}$ is the ratio between viscous forces and capil-

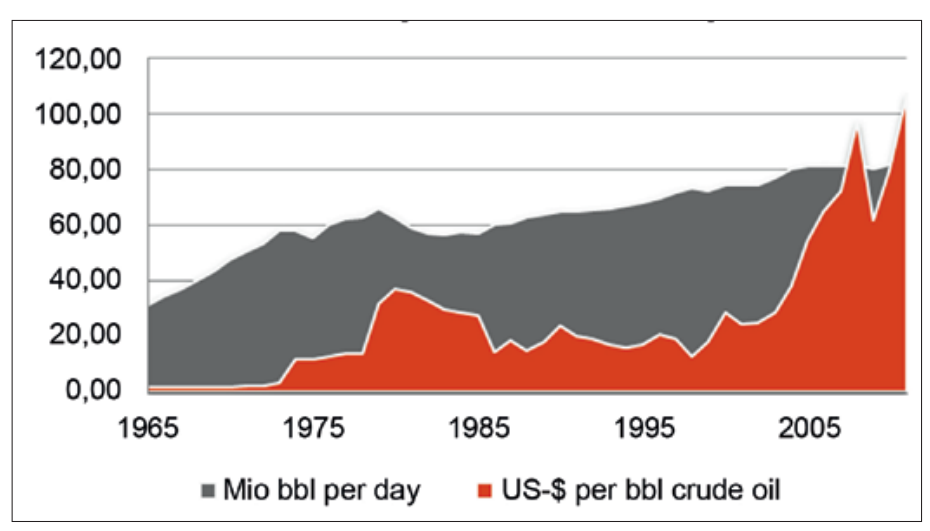

Fig. 2. Crude oil: production and price. 
lary forces that retain the oil in porous media. Fig. 3 illustrates a qualitative picture of the experimentally found microscopic displacement efficiency in dependence of capillary number $N$. The microscopic displacement efficiency represents how easily oil is removed. As presented by Shah, the form of the curve relies on the pore size distribution. ${ }^{[9]}$ For example a narrow distribution leads to a shallow slope of the curve. At the end of water flooding the capillary number $N_{c}$ is around $10^{-6}$. Displacement efficiency is around onethird, which is in good correlation with the recoverable oil by primary and secondary production methods. To increase ultimate oil recovery, the capillary number has to be increased by several orders of magnitude. In other words, we need to climb closer to the top of the S-curve. The formula in Fig. 3 discloses ways in which this target can be achieved for water-wet conditions. The capillary number $N_{c}$ is proportional to the viscosity and velocity of displacing phase and inversely proportional to the interfacial tension. Viscosity can be increased by applying a thickener for the water phase. However, this alternative is limited by the maximum pressure that can be applied to the reservoir without damaging it, and the energy needed to displace a viscous fluid. More promising is the option to decrease interfacial tension between oil and water by 3-4 orders of magnitude. This mobilizes trapped oil and thereby lowers remaining oil saturation significantly.

The importance of the interfacial tension can be explained by the Laplace equation, as shown in Fig. 4. An oil droplet has to be deformed to pass the pore neck of a water-wet stone. As pressure is inversely proportional to the radius of a sphere, the pressure of spherical segment with radius $r_{1}$ is larger than pressure of the spherical segment with radius $r_{2}$. This means that a capillary pressure prevents flow of the oil droplet. Capillary pressure can be minimized by lowering interfacial tension, $\sigma$.

\section{Thickening of Water with Polymers}

An effective way to thicken water is to dissolve high molecular weight and/or stiff polymers. Aqueous solutions of such polymers improve sweep efficiency by mobility control as shown in Fig. 5.

Standard thickeners like poly acrylates known from other applications cannot be used, because salinity of the reservoir impedes the ability of the polymer to extend and viscosify. Ions in the water shield anionic groups, which are needed for electrostatic repulsion and thereby expansion of the polymer chain. In the presence of small amounts of water hardness, the polymer chain is wrapped around bivalent cat-

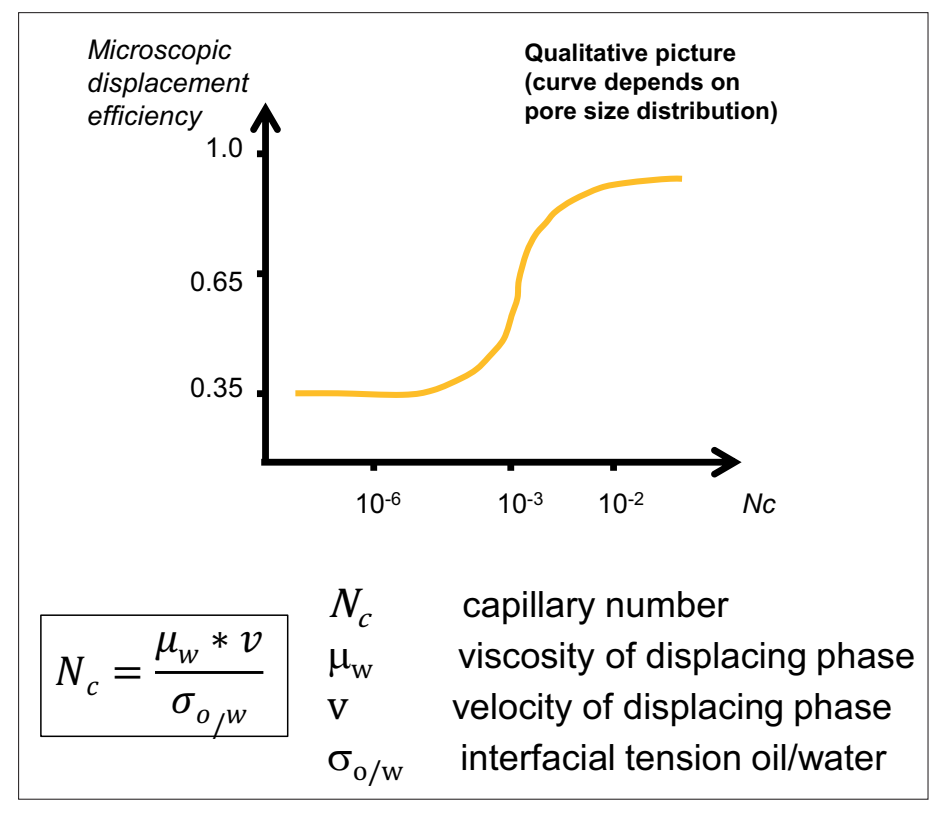

Fig. 3. The dependence of the microscopic displacement efficiency on the capillary number.

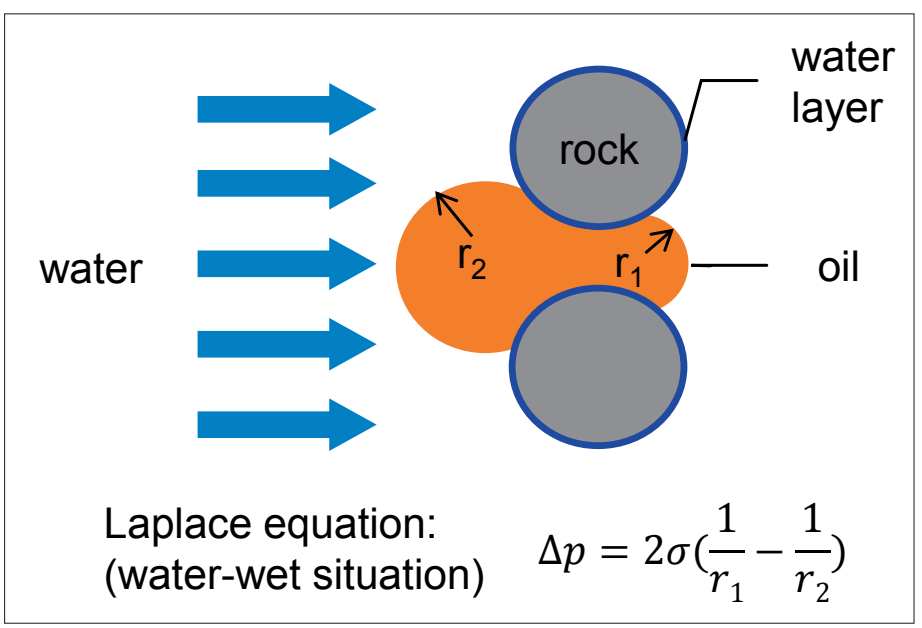

Fig. 4. Laplace equation.

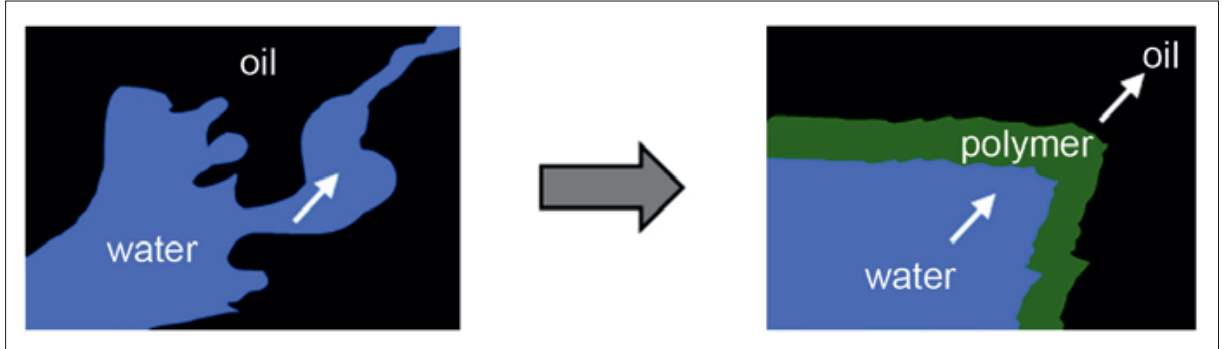

Fig. 5. Effect of polymers.

ions and viscosity is decreased further (the polymer could even precipitate). Partially hydrolyzed high molecular weight poly acrylamides are more salt tolerant and provide suitable viscosity in the presence of even few 10000s ppm total dissolved salt (TDS). However, a further increase of salinity leads to decrease in viscosity and increase in adsorption into the formation of rock. Increase of temperature leads to a decrease in viscosity, too. At temperatures of $100^{\circ} \mathrm{C}$ and higher the polymer starts to chemically degrade by hydrolysis (transformation of acrylamide groups into carboxylic acid groups), and tolerance to water hardness is lost. The biopolymer xanthan has salt tolerant hydroxyl groups, and viscosity is not affected even at high salinity. However, xanthan is not widely used because of its limited temperature stability and because of severe injection issues caused by insoluble residual biomass particles from the fermentation production process. 


\section{Lowering of Interfacial Tension with Surfactants}

Surfactants can mobilize physically trapped oil by decreasing interfacial tension. This is schematically shown in Fig. 6.

As decrease of the interfacial tension between oil and water has to be by several orders of magnitude, a unique surfactant design is needed. The lowest interfacial tension between oil and water is achieved when a so-called 'microemulsion Winsor type III' is formed, which corresponds to the state where the surfactant likes or dislikes equally the oil and the water. Surfactant is then very efficient in stabilizing the oil-water interface and thereby lowers interfacial tension to ultralow values. The microemulsion state is attained at specific temperature and salinity, and for the flooding to be successful these should match the reservoir conditions. Thus, a tailor-made surfactant formulation is needed for each reservoir.

Surfactant performance can be influenced by reservoir and crude oil characteristics. For example temperature and salinity can affect its solubility in water and its tendency to adsorb at the interface. In addition, the surfactant tail has to be hydrophobic enough to interact with the crude oil components (reminder: crude oil is different for every reservoir). As crude oil usually contains more hydrophobic compounds than dirt in washing and cleaning applications, the hydrophobic surfactant tail has to contain more than the usual 12-13 alkyl carbon atoms found in household detergents. Otherwise, reduction of interfacial tension is rather small (e.g. from $20 \mathrm{mN} / \mathrm{m}$ to $1 \mathrm{mN} / \mathrm{m}$ ). Furthermore, surfactant can be trapped by adsorption onto the rock or by formation of viscous aggregates. To offer solutions for the different oil fields a tool box of surfactants is needed. This allows the design of suitable surfactant formulations matching reservoir conditions. Anionic surfactants such as organic sulfonates (like olefin sulfonates or alkyl benzene sulfonates) and alkyl ether sulfates and non-ionic surfactants such as alkyl ethoxylates are used most often.

The use of bases such as sodium carbonate or sodium hydroxide transforms carbonic acids (or their esters) present in crude oils into natural surfactants. These surfactants are cheap, because the bases are inexpensive, but interfacial tension reduction is not large enough. Therefore, a synthetic surfactant is needed. A suitable combination of both delivers the needed reduction of interfacial tension. In addition, use of a base reduces adsorption rate of anionic surfactants on sandstone. The rock surfaces become more negatively charged and thus repel the anionic surfac-

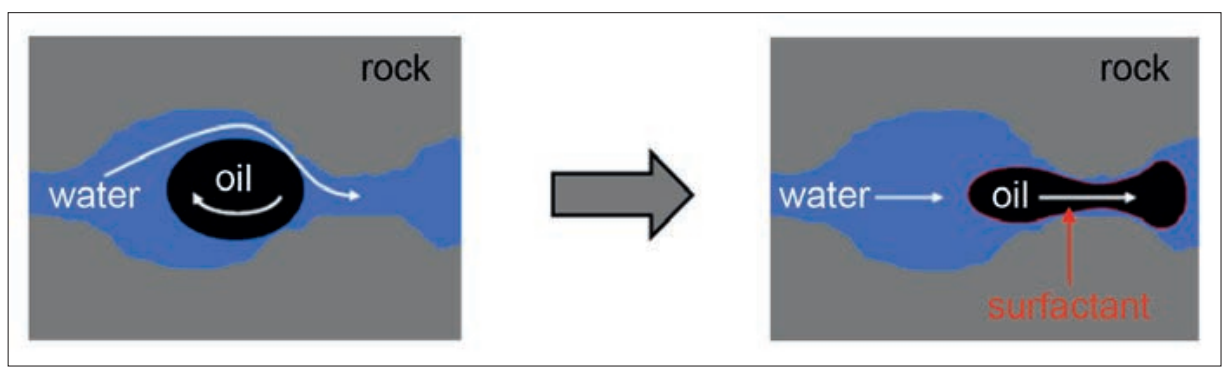

Fig. 6. Effect of surfactants.

tant. However, there are several limitations for alkali. It cannot be used in presence of hard water, and softening of water can be very expensive in the case of medium or high salinity fields. Alkali can also interact with clays (swelling) and can lead to formation of scale, which could block the formation. Also, the formation of very viscous water-in-oil emulsions can be problematic if too much natural surfactant is formed by application of a high amount of alkali. This can cause plugging of the formation and delayed oil-water-separation of produced liquid.

\section{Status of Polymers and Surfactants in CEOR}

As development of surfactant formulations matching reservoir conditions is more time- and resources-consuming, the 'easier' polymer technology has been applied earlier on large scale. On the other side, production of additional OOIP is limited as explained in sections before.

Today, high molecular weight partially hydrolyzed poly acrylamide is used in CEOR. Suppliers of such material are $S N F, B A S F$ and Hengju. This chemical class was used first in USA, but the breakthrough occurred during the 1990s in China. ${ }^{[10,11]}$ The Chinese oil field Daquing (PetroChina, field discovered 1959) has offered suitable conditions for polymer flooding at medium temperature $\left(\sim 45^{\circ} \mathrm{C}\right)$ and low salinity $(<7000 \mathrm{ppm}$ TDS). Oil viscosity is around $9 \mathrm{mPas}$ at reservoir conditions. By 2004 more or less half of the area has been flooded with polymer. Incremental oil recovery has been between 10-12\% OOIP (based on the available 3.6 billion bbl OOIP). The second largest field implementation in China has been at the Shengli oil field (Sinopec). Polymer flooding has led to additional recovery of $\leq 10 \%$ OOIP (other parts of the field have more challenging conditions).

Beside China, large-scale polymer flooding is performed nowadays in Canada. ${ }^{[12,13]}$ The Pelican Lake field contains heavy oil $\left(14^{\circ} \mathrm{API}, \sim 2000 \mathrm{mPas}\right.$, roughly 4 billion bbl OOIP), ${ }^{[12,14]}$ and the temperature and salinity are low. Primary recovery gave around 5\% OOIP. Cenovus started polymer flooding pilots in 2004, CNRL started in 2005, and both were successful. CNRL expects an increase of ultimate recovery to $17 \%$ OOIP. ${ }^{[12]}$ Both companies have increased the number of polymer injector wells (and are continuing to do so) - e.g. Cenovus has around 170 wells injecting polymer (76 in 2008) and $C N R L$ had planned to drill another 63 polymer injector wells in 2012.[13-15]

For surfactants, several pilot trials are known. Mostly a combination of alkaline, surfactants and polymer (ASP-flooding) is used. Surfactant and alkaline deliver ultralow interfacial tension and polymer gives the mobility control. Usually a slug containing the three components is injected first followed by a second slug of polymer only. For example, the former Swiss company Ciba Specialty Chemicals (now part of BASF) delivered hydrolyzed poly acryl amide to two ASP-pilots in the Cambridge field (USA) and the Daquing field (China). ${ }^{[16,17]}$ The pilot in Daquing has shown production of another $18 \%$ OOIP due to ASP flooding. In the case of Cambridge the combination of primary, secondary and tertiary recovery led to production of $60 \%$ OOIP. Several other pilots in Daquing reported up to 25\% OOIP incremental recovery rate for ASP flooding. Beside in China, ASP pilots have also been conducted in North America (USA and mainly Canada). Canadian oil producer Cenovus started a pilot in 2007 at a small part ( 3 million bbl OOIP) of the oil field Suffield. ${ }^{[18]}$ Primary and secondary recovery were $\sim 25 \%$ OOIP, while ASP-flooding led to production of another $~ 14 \%$ OOIP. As it is more than 10\% OOIP and thereby economical, Cenovus has decided to triple pilot size in another heavy oil pool. Another Canadian oil company - Husky - already has several ASP-flooding projects at their fields Gull Lake, Fosterton, Warner, and Crowsnest.[15]

\section{Promising New Products to Match Challenging Field Conditions}

In 2011 new polymers with promising performance in laboratory tests were pre- 
sented. ${ }^{[19,20]}$ They are targeted to demanding oil fields with high salinity.

$B A S F$ has developed a hydrophobic associative acrylamide-based copolymer, which shows much higher viscosity than partially hydrolyzed poly acrylamide in presence of seawater (35000 ppm TDS) or high salinity water (186000 ppm TDS). ${ }^{[19]}$ In contrast to many other hydrophobic associative polymers for CEOR, it has an unusual thermothickening behavior with a maximum value around $60{ }^{\circ} \mathrm{C}$. This makes it interesting for application at elevated temperatures.

Wintershall has presented new test results on Schizophyllan, [20] a homo-glucan produced by fermentation. Due to its tertiary structure (rigid triple helix) this biopolymer can be used even under very harsh conditions - high salinity and high temperature of up to $130^{\circ} \mathrm{C}$. Performance is currently evaluated in a field test in the German oilfield Bockstedt, which has a salinity of around 186000 ppm TDS.

\section{Outlook}

As described in the last two chapters, application of surfactants and polymers can lead to re-vitalization of matured reservoirs. The number of CEOR projects is growing strongly. The direction for further development of CEOR is to offer solutions even for harsh field conditions. All these points illustrate that CEOR is an innovation with the potential of strong impact on future energy supply.

\section{Acknowledgements}

The author would like to thank Dr. G. Alvarez Jürgenson, Dr. S. Stein, Dr. J. Tinsley, Dr. G. Brodt, Dr. F. Haunert, Dr. M. Kienle, Dr. B. Raether, and Dr. X. Beyrich-Graf for fruitful discussions and BASF SE for permission to publish this paper.

Received: August 8, 2013

[1] D. Yergin, 'Der Preis', Fischer, Frankfurt, 1993

[2] International Energy Agency, 'World Energy Outlook 2012 - Executive Summary', www. worldenergyoutlook.org, 2012

[3] B. Albrecht, H. Aubel, M. von Baratta, S Brander, B. Conrad, W. Eschenhagen, S. Jansen, W. Jung, S. Kinder, E. Kraft, H. Krämer, B.-O. Manig, P. Rotmann, M. Unger-Kunz, 'Der Fischer Weltalmanach 2010', Fischer, Frankfurt, 2009.

[4] ExxonMobil Central Europe Holding $\mathrm{GmbH}$, 'Energieprognose 2012-2040', www. exxonmobil.de, 2011.

[5] D. Yergin, 'The Quest', The Penguin Press, New York, 2011.

[6] M. Hartschen, J. Scherer, C. Brügger, 'Innovationsmanagement: Die 6 Phasen von der Idee zur Umsetzung', GABAL-Verlag $\mathrm{GmbH}$, Offenbach, 2009.

[7] L. W. Lake, 'Enhanced Oil Recovery', Prentice Hall, Englewood Cliffs, 1989

[8] BP, 'BP Statistical Review of World Energy June 2011', http://www.bp.com/statisticalreview, 2012.

[9] D. O. Shah, 'Surface Phenomena in Enhanced Oil Recovery', Plenum Press, New York, 1981.

[10] H. L. Chang, Z. Q. Zhang, Q. M. Wang, Z. S. Xu, Z. D. Guo, H. Q. Sun, X. L. Cao, Q. Qiao, J. Petroleum Techno. 2006, $58,84$.

[11] J. J. Sheng, 'Modern Chemical Enhanced Oil Recovery', Gulf Professional Publishing, Oxford, 2011.

[12] CNRL, http://www.cnrl.com/operations/northamerica/north-american-crude-oil-and-ngls/ pelican-lake-crude-oil.html, 2012
[13] Cenovus, http://www.cenovus.com/operations/ technology/polymer.html, 2012.

[14] A. Zaitoun, http://www.spe.org/dl/docs/2010/ AlainZaitoun.pdf, 2010

[15] http://www.newtechmagazine.com/index.php/ news/feature/4-eor-s-quiet-revolution, 2011.

[16] J. Vargo, J. Turner, B. Vergnani, M. J. Pitts, K. Wyatt, H. Surkalo, D. Patterson, SPE 68285, SPE Reservoir Eval. \& Eng. 2000, 3, 552.

[17] G. Shutang, L. Huabin, Y. Zhenyu, M. J. Pitts, H. Surkalo, K. Wyatt, 'Alkaline/Surfactant/ Polymer Pilot Performance of the West Central Saertu, Daqing Oil Field', SPE 35383, SPE/ DOE Symposium on Improved Oil Recovery, Tulsa, 1996.

[18] http://www.stockhouse.com/bullboards/ MessageDetailThread.aspx? $p=0 \& m=2884155$ $8 \& r=0 \& s=W E E \& t=L I S T, 2010$.

[19] R. Reichenbach-Klinke, B. Langlotz, B Wenzke, C. Spindler, G. Brodt, 'Hydrophobic Associative Copolymer with Favorable Properties for the Application in Polymer Flooding', SPE 141107, SPE International Symposium on Oilfield Chemistry, The Woodlands, 2011.

[20] B. Leonhardt, F. Visser, E. Lessner, B. Wenzke, J. Schmidt, 'From Flask to Field - The Long Road to Development of a New Polymer', $16^{\text {th }}$ European Symposium on Improved Oil Recovery, Cambridge, 2011. 